\title{
THE AMELIORATING EFFECT OF EXOGENOUS MELATONIN ON URINARY BLADDER FUNCTION IN HYPEROSMOLAR BLADDER OVERACTIVITY AND ITS INFLUENCE ON THE AUTONOMIC NERVOUS SYSTEM ACTIVITY
}

\author{
Kajetan Juszczak ${ }^{1,2}$, Agata Ziomber ${ }^{1}$, Anna Machowska ${ }^{1}$, Agata Furgata', Lukasz Dobrek ${ }^{1}$, Marek Wyczótkowski², \\ Piotr J. Thor ${ }^{1}$
}

Jagiellonian University, Medical College, Cracow, Poland: Department of Pathophysiology'; Rydygier Memorial Hospital, Cracow, Poland: Department of Urology ${ }^{2}$

\begin{abstract}
Summary: This study was designed to investigate the effects of melatonin on the bladder hyperactivity in hyperosmolar-induced overactive bladder (OAB) rats. Additionally, the influence of melatonin on the autonomic nervous system (ANS) using heart rate variability (HRV) analysis was assessed. 40 rats were divided into four groups: I - control ( $n=12$ ), II - rats with hyperosmolar $\mathrm{OAB}(\mathrm{n}=6)$, III - rats with melatonin pretreatment and hyperosmolar OAB ( $\mathrm{n}=6)$ and IV - control with melatonin pretreatment $(n=6)$. In group III and IV melatonin in dose of $100 \mathrm{mg} / \mathrm{kg}$ was given. HRV measurements in 10 rats, as follow: control $(n=2)$, control after melatonin treatment $(n=2)$, rats with hyperosmolar OAB without $(n=3)$, and after $(n=3)$ melatonin treatment were conducted. This study demonstrates marked influence of melatonin on urinary bladder activity in hyperosmolar-induced OAB rats. These rats showed significantly reduced the detrusor motor overactivity resulting in the improvement of cystometric parameters after melatonin treatment when compared to the control, as follow: a significant increase of intercontraction interval (70\%) and functional bladder capacity (67 \%), as well as a decrease of the basal pressure, detrusor overactivity index and motility index of $96 \%, 439 \%$ and $40 \%$, respectively. ANS activity analysis revealed sympathetic overactivity in $\mathrm{OAB}$ rats, and parasympathetic superiority in melatonin treated $\mathrm{OAB}$ rats. Melatonin treatment in rats with hyperosmolar OAB (group III) caused significant increase of nuHF parameter (from $51.00 \pm 25.29$ to $76.97 \pm 17.43$ ), as well as a decrease of nuLF parameter (from $49.01 \pm 25.26$ to $23.03 \pm 17.43$ ) and LF/HF ratio (from $1.280 \pm 0.980$ to $0.350 \pm 0.330$ ). In conclusion, melatonin suppresses hyperosmolar OAB, and modulates ANS activity by inhibition of the sympathetic drive. Therefore, melatonin may become a useful agent for OAB management.
\end{abstract}

Key words: Melatonin; Hyperosmolarity; Overactive bladder; Cystometry; Rats; Heart rate variability; Autonomic nervous system

\section{Introduction}

The pathophysiology of overactive bladder $(\mathrm{OAB})$ is multifactorial. Although, the two pivotal myogenic (alterations in bladder smooth muscle contractility and excitability) and neurogenic (increased or sensitized sensory transmission, abnormalities in spinal and supraspinal control) basis for the $\mathrm{OAB}$ development have been proposed $(4,8,28)$. The neurogenic theory explains that the backgrounds for $\mathrm{OAB}$ seems to be partially related to alterations in bladder afferent nerve fibres localized within the bladder mucosa.

Animal studies revealed that the bladder mucosa is characterized by a significantly lower concentration of highenergy phosphates and higher oxidative metabolic rate than the detrusor smooth muscle. This facts point that the bladder mucosa is significantly more sensitive to anoxia than is the bladder smooth muscle $(13,18)$. Azadzoi et al. (2) study revealed that long-term arterial insufficiency leads to bladder neuropathy via ischemia, hypoxia and oxidative stress. OAB under the ischemic condition generates neurotoxic oxidative and nitrosative products. Neurodegeneration is postulated to be an end stage phenomenon in ischemia induced bladder overactivity. The increased sensitivity of urothelium to different stimuli (e.g. hypoxia, ischemia, hyperosmotic agents, etc.) would indicate that bladder afferents (pain, altered sensations, reflex contractions) might be activated at levels of hypoxia/ischemia that have no direct effect on bladder smooth muscle function.

Therefore, a novel strategies for therapeutic approach of $\mathrm{OAB}$ based on: 1) reducing the phasic increase in intracellular calcium that causes the activation of calcium activated hydrolytic enzymes, 2) stabilizing the neuronal or smooth muscle membrane components that are hydrolyzed by the activated enzymes; or 3 ) employing free radical scavengers that reduce the activation of cellular lipid peroxidases and the reperfusion injury, seem to be crucial (19).

Melatonin shows multiple biological action potential. Melatonin and several of its metabolites have been shown to 
act as antioxidant and cytoprotective agents by reducing the oxidative stress directly by acting as a free radical scavenger (30), and also by activating several antioxidant systems (31). Also, some papers described that autonomic nervous system (ANS) in patients with overactive bladder is altered and may be a factor in disturbed bladder function (7). Melatonin's influence on peripheral receptors may be triggered due to the alterations in autonomic activity, connected with the inhibition of the sympathetic branch of the ANS.

\section{Purpose}

This study was designed to investigate the protective effect of melatonin against hyperosmolar-induced urinary bladder overactivity in rats. Additionally, the influence of exogenous melatonin on the autonomic nervous system activity using heart rate variability recording was assessed.

\section{Material and methods}

Animals. The study was performed on forty adult female Wistar rats (weight: 200-275 g). Rats were housed individually per cage. The animal room was maintained at a constant temperature of $23{ }^{\circ} \mathrm{C}$, humidity and a $12: 12 \mathrm{~h}$ alternating light-dark cycle. They were fed with animal's food (Labofeed; Kcynia, Poland) with any restraint to water. The study has been approved by the Regional Animals Ethical Committee.

Hyperosmolar model of overactive bladder in rats. The bladder overactivity was induced by constant intravesical infusion of hyperosmolar solution of saline of its concentration at $2080 \mathrm{mOsm} / 1$ and at a rate of $0,046 \mathrm{ml} / \mathrm{min}$, as previously described (15).

Anaesthesia. All the surgical procedures and urodynamic studies were performed under anaesthesia with intraperitonealy injection of $1,2 \mathrm{~g} / \mathrm{kg}$ urethane (Sigma-Aldrich, St. Louis, USA) $(9,16)$.

Surgical procedure. Bladder catheter implantation: under urethane anaesthesia, the abdomen was opened through a midline incision and the bladder end of the polyethylene catheter (o.d. $0,97 \mathrm{~mm} /$ i.d. $0,58 \mathrm{~mm}$; BALT, Poland) was passed through a $1 \mathrm{~mm}$ incision at the apex of the bladder dome and secured in place by silk ligature $4-0$, as previously described $(9,16)$.

Urodynamic studies. Cystometry was performed under urethane anaesthesia after a $1 \mathrm{~h}$ recovery period from the surgical procedure. Room temperature isotonic (group I and IV) or hyperosmolar (group II and III) saline solution was infused at a rate of $0,046 \mathrm{ml} / \mathrm{min}$. continuously into the bladder. The free end of the implanted catheter was connected via T-stopcock to a pressure transducer (UFI, MorroBay, CA, USA) and injection pump (Unipan 340A, Poland). Cystometry was recorded using ML110-BridgeAmp (ADInstruments, Australia) hardware and PowerLab/8SP (ADInstruments, Castle Hill, Australia) software, as previously described $(14,17)$.
Study protocol. All animals were randomly divided into four groups: group I - control group $(n=12)$, group II - rats with hyperosmolar OAB $(n=6)$, group III - rats with melatonin pretreatment and hyperosmolar OAB $(n=6)$ and group IV - control group with melatonin pretreatment $(n=6)$. Cystometry was performed $1 \mathrm{~h}$ after surgical procedure in all groups. In group III and IV melatonin (SigmaAldrich, Germany) in dose of $100 \mathrm{mg} / \mathrm{kg}$ was given intraperitoneally ( $1 \mathrm{ml}$ of melatonin solution) after catheter implantation within 20 minutes before hyperosmolar or isotonic saline infusion, respectively.

The measurements in each animal represent the average of five bladder micturition cycles, after obtaining repetitive voiding. The following cystometrogram's (CMGs) parameters were recorded: $\mathrm{BP}$ - basal pressure $\left(\mathrm{cmH}_{2} 0\right)$, PT - threshold pressure $\left(\mathrm{cmH}_{2} 0\right)$, MVP - micturition voiding pressure $\left(\mathrm{cmH}_{2} 0\right)$, ICI - intercontraction interval (min.), Compliance $\left(\mathrm{ml} / \mathrm{cmH}_{2} 0\right), \mathrm{fBC}$ - functional bladder capacity $(\mathrm{ml})$. Moreover we calculated $\mathrm{MI}-$ motility index $\left(\mathrm{cmH}_{2} \mathrm{O} \times \mathrm{s} / \mathrm{min}\right.$. $)$ in 10-minutes intervals. In addiction we analysed DI - detrusor index $\left(\mathrm{cmH}_{2} \mathrm{O} / \mathrm{ml}\right)$ in group I and DOI - detrusor overactivity index $\left(\mathrm{cmH}_{2} \mathrm{O} / \mathrm{ml}\right)$ in other groups (16), depicted as quotient of the sum of amplitudes of all detrusor contractions during filling phase and functional bladder capacity (1).

The "sham" group for group III (rats with melatonin pretreatment and hyperosmolar $\mathrm{OAB}$ ) and IV (control group with melatonin pretreatment) were also tested. We revealed no significantly changes in CMG and HRV parameters in rats with hyperosmolar $\mathrm{OAB}+$ saline i.p. pretreatment (control to group III), as well as in case of control rats with saline i.p. pre-treatment (control to group IV). Therefore, we detailed description of these results was omitted.

HRV studies. The experimental procedures were conducted by using heart rate variability (HRV) measurements in 10 female Wistar rats, as follow: control rats $(n=2)$, control rats after melatonin treatment $(n=2)$, rats with hyperosmolar OAB $(n=3)$, and rats with hyperosmolar OAB after melatonin treatment $(n=3)$. To the HRV analysis there was used PowerLab (ADInstruments, Australia) set. 10-minutes intervals of ECG recording were analysed for HRV and ANS activity estimation. The following HRV parameters were taken into consideration: $\mathrm{mRR}$ (ms), HR (BPM), SDNN (ms), RMSSD (ms), VLF $\left(\mathrm{ms}^{2}\right)$ - power of very low frequency $(0,0033-0,04 \mathrm{~Hz}), \mathrm{LF}\left(\mathrm{ms}^{2}\right)$ - power of low frequency $(0,04-0,15 \mathrm{~Hz})$, LFnu ( \%) - LF power in normalized units LF/(TP - VLF) x 100, HF $\left(\mathrm{ms}^{2}\right)$ - power of high frequency $(0,15-0,4 \mathrm{~Hz})$, HFnu ( \%) - HF power in normalized units $\mathrm{HF} /(\mathrm{TP}-\mathrm{VLF}) \times 100, \mathrm{LF} / \mathrm{HF}$ - ratio of LF power to HF power, LF/HFnu ( \%) - normalized ratio of LF power to HF power, PSD (TP) $\left(\mathrm{ms}^{2}\right)$ - total power of spectrum of the RR variability. Normalized units are used to emphasize the reciprocal action of the parasympathetic and sympathetic limbs of ANS and to minimize the effect of changes in total power on the values of LF and HF components (17). The HRV parameters were analyzed using software application Chart Pro 5. 
Tab. 1: Cystometrogram's parameters in normal rats (group I), in hyperosmolar OAB rats without and after melatonin treatment (group II and III, respectively) and in normal rats after melatonin treatment (group IV).

\begin{tabular}{|c|c|c|c|c|c|}
\hline & $\begin{array}{l}\text { Group I: } \\
\text { CONTROL }\end{array}$ & $\begin{array}{c}\text { Group II: } \\
2080 \mathrm{mOsm} / 1 \\
\mathrm{NaCl}\end{array}$ & $\begin{array}{c}\text { Group III } \\
2080 \text { mOsm/1 NaCl } \\
+ \text { MELATONIN }\end{array}$ & $\begin{array}{c}\text { Group IV } \\
\text { CONTROL } \\
+ \text { MELATONIN } \\
\end{array}$ & $P$ Value \\
\hline $\mathrm{BP}\left(\mathrm{cmH}_{2} \mathrm{O}\right)$ & $1.41 \pm 0.60$ & $3.07 \pm 0.16$ & $1.57 \pm 0.17$ & $1.48 \pm 0.30$ & $0.000^{* \#}$ \\
\hline PT $\left(\mathrm{cmH}_{2} \mathrm{O}\right)$ & $5.70 \pm 1.22$ & $6.12 \pm 0.26$ & $5.42 \pm 0.67$ & $5.53 \pm 0.70$ & NS \\
\hline MVP $\left(\mathrm{cmH}_{2} \mathrm{O}\right)$ & $27.4 \pm 4.9$ & $25.9 \pm 4.9$ & $22.4 \pm 3.4$ & $27.6 \pm 3.2$ & $\mathrm{NS}$ \\
\hline ICI (min.) & $5.28 \pm 1.55$ & $2.59 \pm 0.26$ & $4.40 \pm 0.87$ & $5.27 \pm 0.84$ & $0.001^{*} ; 0.051^{\#}$ \\
\hline Compliance $\left(\mathrm{ml} / \mathrm{cmH}_{2} \mathrm{O}\right)$ & $0.059 \pm 0.019$ & $0.040 \pm 0.008$ & $0.054 \pm 0.013$ & $0.062 \pm 0.013$ & NS \\
\hline fBC (ml) & $0.240 \pm 0.070$ & $0.120 \pm 0.012$ & $0.200 \pm 0.040$ & $0.243 \pm 0.039$ & $0.001^{*} ; 0.052^{\#}$ \\
\hline $\mathrm{DI} / \mathrm{DOI}\left(\mathrm{cmH}_{2} \mathrm{O} / \mathrm{ml}\right)$ & $121.9 \pm 33$ & $625.8 \pm 101.4$ & $116.1 \pm 32.0$ & $129.6 \pm 24.8$ & $0.000^{* \#}$ \\
\hline $\mathrm{MI}\left(\mathrm{cmH}_{2} \mathrm{O} \times \mathrm{s} / \mathrm{min}.\right)$ & $185.4 \pm 45.9$ & $245.2 \pm 61.5$ & $180.3 \pm 45.5$ & $164.7 \pm 31.5$ & $0.007^{*} ; 0.006^{\#}$ \\
\hline
\end{tabular}

*group II versus group I; \#group II versus group III
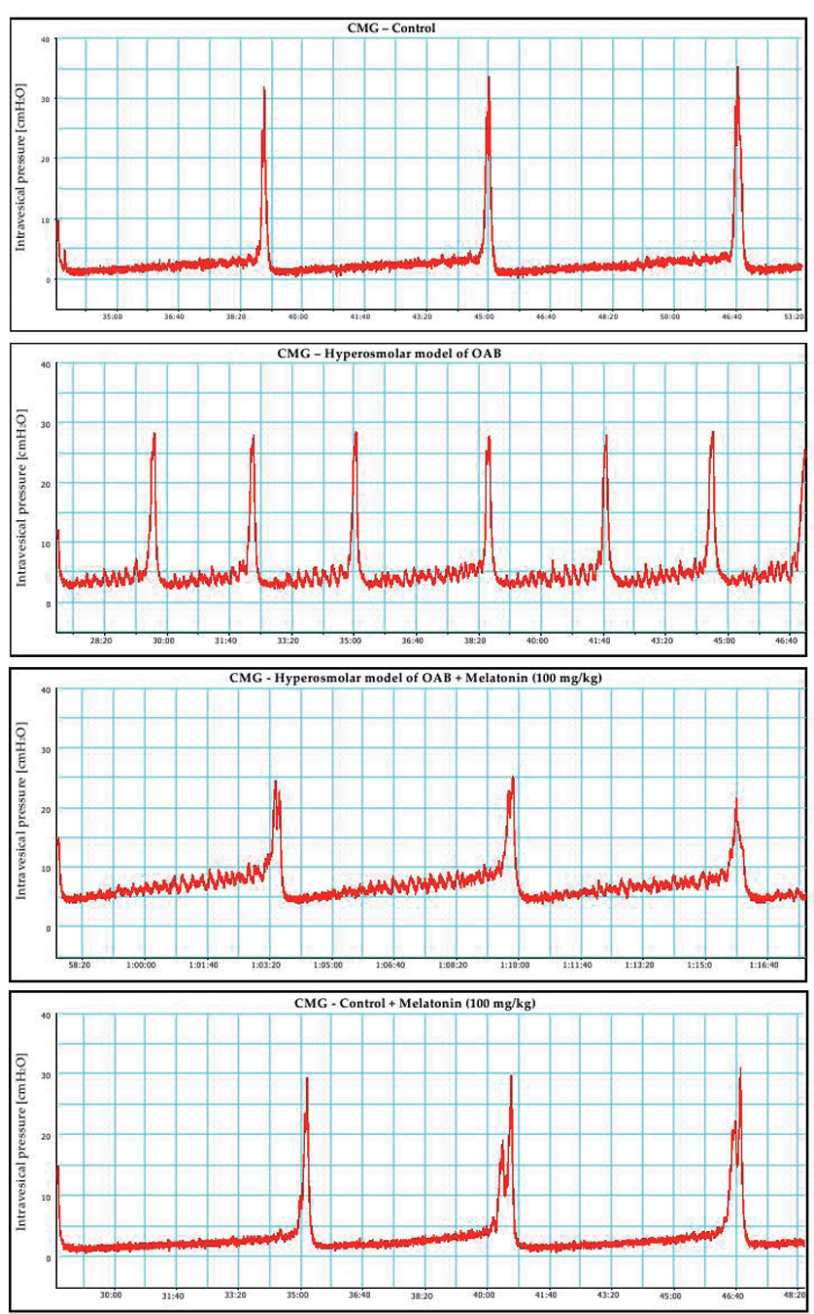

Fig. 1: Cystometrogram's traces in control and with hyperosmolar $\mathrm{OAB}$ rats with and without melatonin treatment. The figure shows 20-minutes interval (horizontal axis). Vertical axis estimates intravesical pressure of $(-5)-40 \mathrm{cmH}_{2} \mathrm{O}$ range.

\section{Group I (control) vs. Group II (hyperosmolar OAB)}

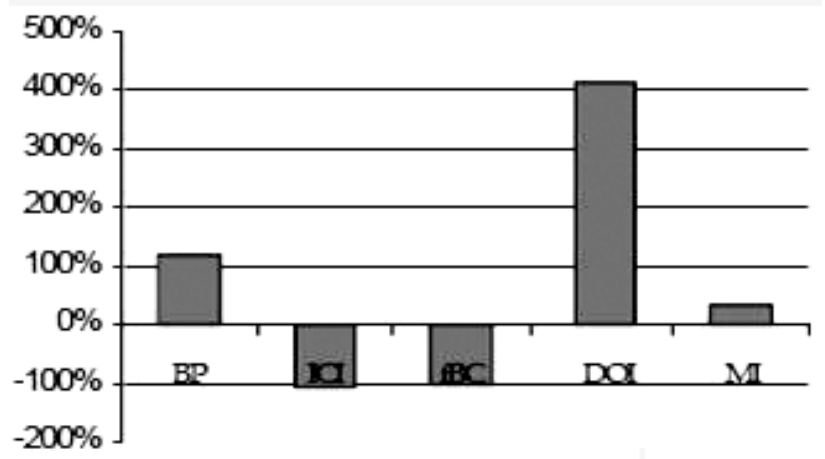

Urodynanic parameters
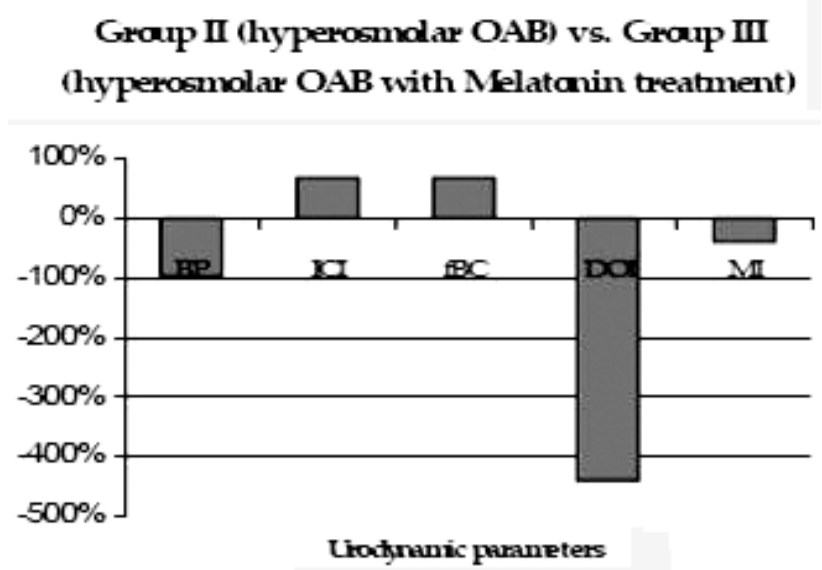

Fig. 2: The percentage of significantly changes of basal pressure (BP), intercontraction interval (ICI), functional bladder capacity (fBC), detrusor overactivity index (DOI) and motility index (MI) in rats with hyperosmolar OAB (group II) compared to normal, healthy rats (group I) and to rats with hyperosmolar $\mathrm{OAB}$ with melatonin treatment (group III). 

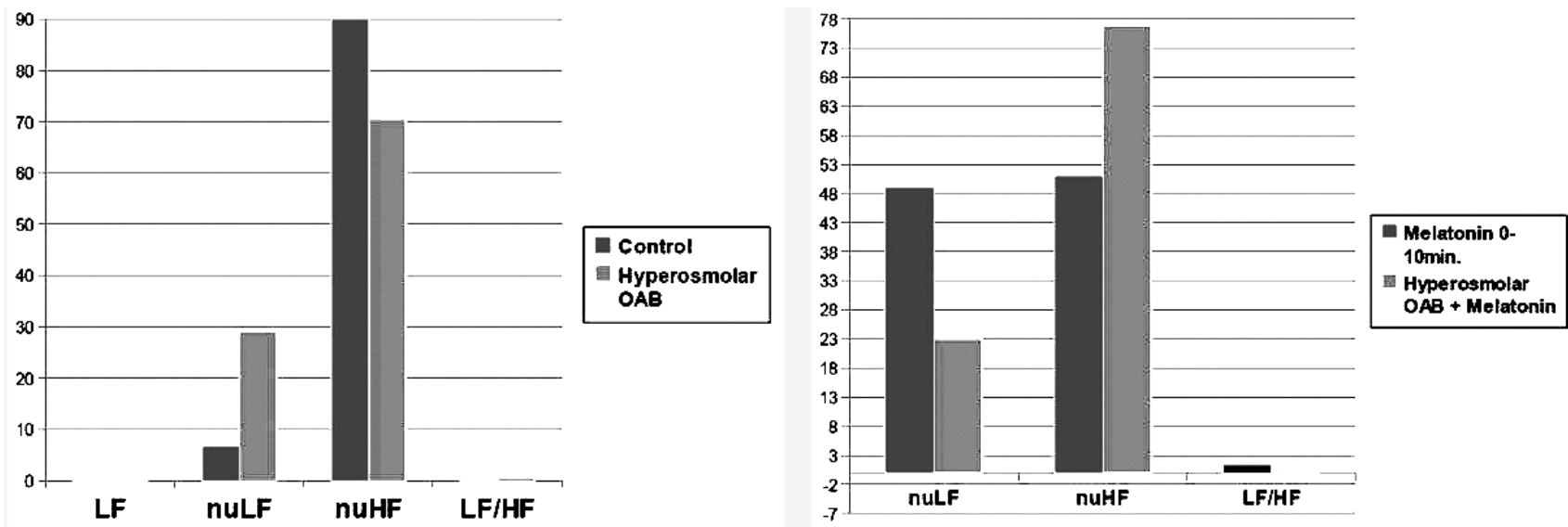

Fig. 3: Mean values of Heart Rate Variability parameters in control and with hyperosmolar overactive bladder rats without and after melatonin $(100 \mathrm{mg} / \mathrm{kg}$ i.p. $)$ treatment.

Statistical analysis. The results are expressed as mean and standard deviation ( \pm SD). Shapiro-Wilk tests were used to test for normal distribution of the data. A KruskalWallis test was utilized for multiple comparisons. MannWhitney U tests were used for post-hoc comparisons with Bonferroni correction of the alpha in order to maintain the overall probability of a type I error at 0.05 . For HRV parameters values analysis the test T-students was used. A p value of $<0.05$ was considered significant. The data were analyzed with SPSS software (version 12.0).

\section{Results}

Effect of hyperosmolar saline intravesical infusion on bladder motor activity - hyperosmolar model of overactive bladder. The hyperosmolar saline $(2080 \mathrm{mOsm} / \mathrm{l})$ intravesical infusion induced bladder motor overactivity. The cystometric curve was similar to the recordings of bladder activity after chemical induction of OAB using cyclophosphamide in acute model (11). We observed a significant decrease of intercontraction intervals ( $104 \%)$ and functional bladder capacity $(100 \%)$. Also an increase of basal pressure $(118 \%)$, detrusor activity $(413 \%)$ and motility index (33\%) were observed (Tab. 1, Fig. 1, Fig. 2). No statistically differenences of threshold, micturition voiding pressure and compliance were obtained.

Effect of melatonin on bladder motor activity in hyperosmolar overactive bladder rats. Intraperitoneally administration of $100 \mathrm{mg} / \mathrm{kg}$ melatonin reduced the detrusor motor overactivity resulting in the improvement of cystometric parameters in hyperosmolar overactive bladder rats. In comparison to hyperosmolar overactive bladder rats, we recorded significantly increase of intercontraction interval $(70 \%)$ and functional bladder capacity (67 \%). The basal pressure, detrusor overactivity index and motility index significantly decreased of $96 \%, 439 \%$ and $40 \%$, respectively. The threshold and maximal voiding pressure, compliance were not significantly changed (Tab. 1, Fig. 1, Fig. 2).
Effect of melatonin on bladder motor activity in normal, healthy rats. The melatonin given intraperitonealy in 100 $\mathrm{mg} / \mathrm{kg}$ dose revealed no distinctive impact on urinary bladder function in normal, healthy rats (Tab. 1, Fig. 1, Fig. 2).

Effect of melatonin on autonomic nervous system (ANS) activity in normal and with hyperosmolar overactive bladder rats. In control group (group I) the intensified activity of parasympathetic branch of ANS occurred. It was characterized by $\mathrm{LF} / \mathrm{HF}$ ratio values $(0.085 \pm 0.100)$ and increased values of nuHF parameter (mean: $92.75 \pm 8.36$ ) in comparison with nuLF parameter (mean: $16.88 \pm 12.92$ ).

In rats with hyperosmolar OAB significant increase of LF parameter (from $0.095 \pm 0.100$ to $0.230 \pm 0.070 ; p=0,019$ ), and $\mathrm{LF} / \mathrm{HF}$ ratio (from $0.085 \pm 0.100$ to $0.579 \pm 0.583$; $\mathrm{p}=0.076$ ), as well as a decrease of nuHF parameter (from $92.75 \pm 8.36$ to $70.43 \pm 25.55 ; \mathrm{p}=0.065$ ). Additionally, HRV analysis of two different intervals of ECG recordings (between 5-15 minutes and 25-35 minutes after hyperosmolar saline intravesical infusion) revealed the slight differences of HRV parameters in the following intervals characterized by decrement of LF parameter values (from $0.230 \pm 0.070$ to $0.124 \pm 0.080 ; p=0,023$ ) and SDNN parameter value (from $4.618 \pm 1.730$ to $2.400 \pm 0.071 ; p=0,026)$ (Fig. 3).

Melatonin treatment in rats with hyperosmolar $\mathrm{OAB}$ (group III) caused significant increase of nuHF parameter (from $51.00 \pm 25.29$ to $76.97 \pm 17.43$ ), as well as a decrease of nuLF parameter (from $49.01 \pm 25.26$ to $23.03 \pm 17.43$ ) and $\mathrm{LF} / \mathrm{HF}$ ratio (from $1.280 \pm 0.980$ to $0.350 \pm 0.330$ ) (Fig. 3). The HRV analysis of two different intervals of ECG recordings (between 5-15 minutes and 25-35 minutes after melatonin administration and hypertonic - group III saline intravesical infusion) revealed no differences of HRV parameters in the following intervals.

Also no significant changes of HRV parameters were observed in the two following intervals of ECG recordings (between 0-10 minutes and 10-20 minutes after melatonin administration and isotonic - group IV saline intravesical infusion). 


\section{Discussion}

The results of the current experiment show that melatonin has protective impact on hyperosmolar-induced urinary bladder overactivity (OAB) in rats. One of the theory of $\mathrm{OAB}$ development is based on the formation of Reactive Oxygen Species (ROSs) in different pathophysiological condition affecting proper urinary bladder function (e.g. bladder outlet obstruction, ischeamia/reperfusion and inflammation processes $)(5,10,20)$. ROSs lead to lipid peroxidation of cellular membranes altering its function (27). The changed cells membrane properties cause the increased excitability of both neuronal and smooth muscle membranes, which directly results in OAB. The loss of lipids in specific cellular membranes can result in denervation, denervation supersensitivity (increased sensitivity of the autonomic receptors to neurohumoral transmission), increased sensitivity of the smooth muscle membrane to myogenic stimulation, and induction of both neurogenic and myogenic overactivity (19).

Melatonin is originally defined as a agent which reduces lipid peroxidation and scavenges ROSs initiating lipid peroxidation $(25,29)$. Also, melatonin has potent antioxidant properties (3). Employing the ROSs scavengers (e.g. melatonin) that reduce the activation of cellular lipid peroxidases and secondarily bladder overactivity seems to be crucial. There are no data considering the influence of melatonin on bladder motor activity and autonomic nervous system function in healthy and hyperosmolar-induced $\mathrm{OAB}$ rats (in vivo). Therefore, based on these facts we established the experiment to determine whether melatonin ameliorates the bladder hyperactivity in hyperosmolar-induced OAB rats.

This study demonstrates marked influence of intraperitoneally administration of melatonin in $100 \mathrm{mg} / \mathrm{kg}$ dose on urinary bladder activity in hyperosmolar-induced $\mathrm{OAB}$ in rats. The rats with hyperosmolar-induced $\mathrm{OAB}$ in this experiment showed significantly reduced the detrusor motor overactivity resulting in the improvement of cystometric parameters after melatonin treatment when compared to the control OAB group. After melatonin treatment the OAB rats revealed significantly increase of intercontraction interval $(70 \%)$ and functional bladder capacity (67 \%). The basal pressure, detrusor overactivity index and motility index significantly decreased of $96 \%, 439 \%$ and $40 \%$, respectively. The distinctive decrease of detrusor overactivity index is caused by inhibition of the non-voiding contractions (NVCs) and elongation of intercontraction intervals after melatonin administration. The symptoms of $\mathrm{OAB}$ are usually attributed to involuntary contractions of the detrusor muscle, as well as the severity of OAB symptoms defines the grade of bladder overactivity, which partly depends on the profile of non-voiding and micturition-voiding induced contractions $(14,23)$. Thus, melatonin seems to be a novel agent reducing OAB symptoms.

Although the exact pathomechanism of melatonin action within the urinary tracts has not yet been elucidated, the ameliorating effects of melatonin on urinary bladder overactivity represent a novel pathway in the pharmacological treatment of OAB. Based on the results of different studies, the potential mechanism of melatonin action in $\mathrm{OAB}$ rats can be taken under the consideration. Firstly, hyperosmolar saline given intravesically can penetrate submucosal layers of urinary bladder and activates capsaicinsensitive $\mathrm{C}$ neurons and consequently induce neurogenic inflammation leading to OAB (15). Masuda et al. (22) revealed that ROSs, especially $\mathrm{H}_{2} \mathrm{O}_{2}$ and $-\mathrm{OH}$, might stimulate capsaicin-sensitive bladder afferent fibres, thereby inducing detrusor overactivity in rats. Thus, the possible mechanism seems to be concerned with C-fibres activity, which relays on scavenge of ROSs by melatonin, in result reducing the afferent $\mathrm{C}$-fibres activity and secondarily the urinary bladder hyperactivity. Secondarily, Semercioz et al. (26) considered the other possible mechanisms of melatonin induced inhibition of urinary bladder contractility may be its interaction with calmodulin or its calcium-channel blocking effects. They observed that melatonin inhibits acetylcholine- and KCI-induced contractions in isolated bladder strips from guinea pigs. Melatonin can bind to $\mathrm{Ca}^{2+}$-activated calmodulin with high affinity, and may prevent it from activating myosin light-chain kinase, leading to decreased contractility (24). Moreover, Gomez-Pinilla et al. (11) obtained that melatonin treatment restored smooth muscle contractility by normalizing $\mathrm{Ca}^{2+}$ signalling and increasing $\mathrm{Ca}^{2+}$ sensitization in age-related changes in the contractility of detrusor smooth muscle. Moreover, the other possible mechanism of melatonin ameliorating action on detrusor hyperactivity is the influence of melatonin on its peripheral and central receptors (MT1 and/or MT2).

The new theory of OAB development concerning with interaction between capsaicin-sensitive bladder afferent nerves and ROSs within the bladder nerves and urothelial layer is strongly supported by the results of Chien CT et al. (5), Masuda et al. (22) and Chien WC et al. (6) experiments. They observed that exogenous substance P via NK1receptor activation enhances the micturition reflex and ROSs release from the inflammatory cells and leads to a OAB. Also the high dose of $3 \% \mathrm{H}_{2} \mathrm{O}_{2}$ given intravesically decreased the micturition voiding pressure immediately and induced dribbling incontinence in rats. In pretreated rats with capsaicin (to achieve the desensitization of afferent $\mathrm{C}$-fibres pathway) the afferent $\mathrm{C}$-fibres responses to $0.3 \% \mathrm{H}_{2} \mathrm{O}_{2}$ were significantly reduced. These facts strongly suggest that capsaicin-sensitive bladder afferent fibres are important in the sensory transduction of ROSs in the urinary bladder (22).

According to neurogenic theory of bladder overactivity development, several studies suggest that one of the various pathophysiological factors responsible for OAB development seems to be a specific dysfunction of the autonomic nervous system. Our preliminary results of ANS activity assessment using HRV recording showed ANS activity disturbance. In comparison with control animals, in the ani- 
mals with hyperosmolar OAB the superiority of sympathetic branch ANS activity was recorded. The melatonin treatment induced ANS changes. Differentially, rats with hyperosmolar $\mathrm{OAB}$ treated with melatonin obtained the overactivity of parasympathetic ANS drive. Study performed on humans by Hubeaux et al. (12) demonstrates the predominance of parasympathetic activity with the bladder emptied and a preponderance of sympathetic activity at the end of bladder filling in women with overactive bladder syndrome. These observations suggest dysfunction in the autonomic balance, as implied in idiopathic overactive bladder syndrome.

Thus, the OAB induced by hyperosmolar saline intravesical infusion might be the result of increased ROSs release from urothelium and inflammatory cells (e.g. mastocytes) within the urinary bladder which indirectly activate the afferent capsaicin-sensitive pathway responsible for $\mathrm{OAB}$ development, as well as a result of autonomic nervous system imbalance. For that reason, further investigations are needed to clarify the contribution of ROSs, ANS and melatonin receptor-mediated pathways in urinary bladder function and pathomechanism of the ameliorating action of melatonin in hyperosmolar-induced $\mathrm{OAB}$ rats.

\section{Conclusion}

In conclusion, our results revealed that melatonin sup presses increased hyperosmolar-induced bladder activity, and modulates the autonomic nervous system activity by inhibition of the sympathetic drive. Therefore, melatonin may become a useful agent for OAB management.

\section{Acknowledgments}

Conflict of interests - None declared.

\section{References}

1. Abrams P. Describing bladder storage function: overactive bladder syndrome and detrusor overactivity. Urology 2003;62(5B):28-37.

2. Azadzoi KM, Yalla SV, Siroky MB. Oxidative Stress and Neurodegeneration in the Ischemic Overactive Bladder. J Urol 2007;178:710-715.

3. Barlow-Walden LR, Reiter RJ, Abe M. Melatonin stimulates brain glutathione peroxidases activity. Neurochem Int 1995;26:497-501.

4. Brading AF. A myogenic basis for the overactive bladder. Urology 1997;50(6A): $57-67$

5. Chien CT, Yu HJ, Lin TB, Lai MK, Hsu SM. Substance P via NK1 receptor facilitates hyperactive bladder afferent signaling via action of ROS. Am J Physiol Renal Physiol 2003;284:F840-51.

6. Chien WC, Hayakawa S, Shimizu K, Chien CT, Lai MK. Catechins prevents substance P-induced hyperactive bladder in rats via the downregulation of ICAM and ROS. Neurosci Lett 2004;367:213-7.

7. Choi JB, Kim YB, Kim BT, Kim YS. Analysis of heart rate variability in female patients with overactive bladder. Urology 2005;65:1109-1113.
8. de Groat WC. A neurologic basis for the overactive bladder. Urology 1997; 50(6A):36-52.

9. Dinis P, Churrua A, Avelino A, Cruz F. Intravesical resiniferatoxin decreases spinal c-fos expression and increases bladder volume to reflex micturition in rats with chronic inflamed urinary bladders. BJU Int 2004;94(1):153-7.

10. Erdem E, Leggett R, Dicks B, Kogan BA, Levin RM. Effects of bladder ischaemia/reperfusion on superoxide dismutase activity and contraction. BJU Int 2005;96:169-74

11. Gomez-Pinilla PJ, Gomez MF, Sward K, Hedlund P, Hellstrand P, Camello PJ, Andersson KE, Pozo MJ. Melatonin restores impaired contractility in aged guinea pig urinary bladder. J Pineal Res 2008:44:416-425.

12. Hubeaux K, Deffieux X, Ismael SS, Raibaut P, Amarenco G. Autonomic nervous system activity during bladder filling assessed by heart rate variability analysis in women with idiopathic overactive bladder syndrome or stress urinary incontinence. J Urol 2007;178(6):2483-7.

13. Hypolite JA, Longhurst PA, Gong C, Briscoe J, Wein AJ, Levin RM. Metabolic studies on rabbit bladder smooth muscle and mucosal epithelium. Mol Cell Biochem 1993;125:35-42.

14. Juszczak K, Królczyk G, Filipek M, Dobrowolski ZF, Thor PJ. Animal models of overactive bladder: cyclophosphamide (CYP)-induced cystitis in rats. Folia Med Cracov 2007;48(1-4):113-123.

15. Juszczak K, Ziomber A, Wyczółkowski M, Thor PJ. Hyperosmolarity alters the micturition: The comparison of urinary bladder motor activity in hyperosmolar and cyclophosphamide-induced models of overactive bladder. Can J Physiol Pharmacol 2010;88(9):899-906.

16. Juszczak K, Ziomber A, Wyczółkowski M, Thor PJ. Urodynamic effects of the bladder C-fiber afferent activity modulation in chronic overactive bladder model rats. J Physiol Pharmacol 2009;60,4:85-91.

17. Juszczak K, Wyczolkowski M, Thor PJ. The participation of afferent $\mathrm{C}$ fibres in micturition reflex regulation. Adv Clin Exp Med 2010;19,1:13-19.

18. Levin RM, Hypolite JA, Haugaard N, Wein AJ. Comparative response of rabbit bladder smooth muscle and mucosa to anoxia. Neurourol Urodyn 1996;15:79-84.

19. Levin RM. Discussion: Potential future pharmacologic approaches. Urology 1997;50(6A):87-89.

20. Lin AT, Yang CH, Chen KK, Chang LS. Detrusor mitochondrial lipid peroxidation and superoxide dismutase activity in partial bladder outlet obstruction of rabbits. Neurourol Urodyn 2005;24:282-7.

21. Malik M. Heart rate variability-standards of measurement, physiological interpretation and clinical care use. Circulation 1996;93(5):1043-65.

22. Masuda H, Kihara K, Saito K, Matsuoka Y, Yoshida S, Chancellor MB, de Groat WC, Yoshimura N. Reactive oxygen species mediate detrusor overactivity via sensitization of afferent pathway in the bladder of anaesthetized rats. BJU Int 2007;101:775-780.

23. Ouslander JG. Management of overactive bladder. N Engl J Med 2004;350: 786-799.

24. Ouyang H, Vogel HJ. Melatonin and serotonin interactions with calmodulin: NMR spectroscopic and biochemical studies, Biochim Biophys Acta 1998;1383:37-47.

25. Pierrefiche G, Topall G, Courboyn G, Henryet I, Laborit H. Antioxidant activity of melatonin in mice. Res Commun Chem Pathol Pharmacol 1993;80:211-23.

26. Semercioz A, Onur R, Ayar A, Orhan I. The inhibitory role of melatonin on isolated guinea-pig urinary bladder: an endogenous hormone effect. BJU Int 2004; 94:1373-1376.

27. Speakman MJ, Brading AF, Gilpin CJ, Dixon JS, Gilpin SA, Gosling JA. Bladder outflow obstruction. A cause of denervation supersensitivity. J Urol 1987;138: 1461-1466.

28. Steers WD. Pathophysiology of overactive bladder and urge urinary incontinence. Rev Urol 2002;4:S7-S18

29. Tan DX, Chen LD, Poeggeler B, Manchester LD, Reiter RJ. Melatonin: a potent, endogeneous hydoxyl radical scavenger. Endocrine J 1993;1:57-60.

30. Tan DX, Manchester LC, Reiter RJ, Plummer BF, Limson J, Weintraub ST, Qi W. Melatonin directly scavenges hydrogen peroxide: a potentially new metabolic pathway of melatonin biotransformation. Free Rad Biol Med 2000;29:1177-1185.

31. Tan DX, Reiter RJ, Manchester LC, Yan MT, El-Sawi M, Sainz RM, Mayo JC, Kohen R, Allegra M, Hardeland R. Chemical and physical properties and potential mechanisms: melatonin as a broad spectrum antioxidant and free radical scavenger. Curr Top Med Chem 2002;2:181-197.

Received: $29 / 10 / 2010$.

Accepted in revised form: 23/01/2011.

\section{Corresponding author:}

Kajetan Juszczak MD, PhD, Departament of Pathophysiology, Medical College, Jagiellonian University, Czysta Street 18, 31-121 Cracow, Poland; e-mail: kajus13@poczta.onet.pl 